\title{
Understanding the Continued Usage of Business e-learning Courses in HK Corporations
}

\author{
Paul Yeung Ernest Jordan \\ Macquarie Graduate School of Management, Macquarie University, \\ Australia \\ e-mail : pyeung@vtc.edu.hk
}

\begin{abstract}
Other research has investigated different aspects of e-learning, e.g. comparing the effectiveness of e-learning with traditional classroom training and on the success of IT or computer skills training. This study focused on how to ensure that individuals continue their usage of business and management e-learning courses for self-development in Hong Kong Corporations. A theoretical framework was developed based on Venkatesh's model of System Usage, Bhattacherjee's Expectation-Confirmation Model and Seddon's re-specification of DeLone and McLean's Information System Success Model. The proposed model was calibrated with 212 valid samples from five corporations in Hong Kong and was validated with 15 questionnaires from a small e-commerce company of 50 staff at a different time. The data supported the model and the model had a moderate explanatory power (R2=37\%) for continued usage. The structural model was not affected by different collection periods (first collection batch vs last collection batch), sample (calibration vs validation), gender (male vs female), position (manager vs non-manager), and computer usage experience ( 10 years or more vs less than 10 years). However, the model was different for groups of different ages (age 36 and above vs below 36 ) and educational levels (university graduates vs non-university graduates). Further research and the business implications for improving the continued usage of business e-learning courses are discussed.
\end{abstract}

Key words : e-learning, user satisfaction, continued IT usage, technology acceptance, survey research, consumer behavior 


\section{Introduction}

Corporations in Hong Kong have increased their emphasis on e-learning in the past five years. Because of its distinctive competitive advantages, such as cost-saving for arranging staff to learn as a group from various locations, and participants can learn at their own pace at anytime anywhere, e-learning is a growing trend in the learning field. However, some corporations in Hong Kong face a problem of poor utilization of the e-learning solution which is also a concern in US (e.g. [4] and [5]).

Over the past two decades, a significant body of research has focused on identifying various factors that influence user acceptance behaviors. According to Bhattacherjee [2], the eventual success of a new technology depends not just on the initial adoption of the system but more on the users' continued usage of the IS.

There has been research on the success of using IT or computer skills training (e.g. [6] and [7]). The objective of this study is to identify the factors affecting continued usage of business and management e-learning courses at an individual level and to provide empirical validation of the proposed model. This study can provide practitioners with deeper insights on the factors that influence user satisfaction and how to encourage continued usage behaviors.

\section{Key definition}

The evolving definition of e-learning used in this paper is defined as the instructional content or learning experiences delivered or enabled by internet technology to enhance an individual's knowledge and performance. This definition is derived from the Commission on Technology and Adult Learning by the American Society for Training and Development and National Governors Association, US [8, p.7].

\section{The context}

Most corporations in Hong Kong prescribed business e-learning courses for staff development activity. The employees are all adult. The usage of the e-learning courses is voluntary, i.e. staff are not forced to complete any courses. The usage is also volitional, i.e. there is no barrier that would prevent the individual from learning if he or she chooses to do so. The business and management e-learning course is different from the commonly researched IT/computer training e-learning courses as the participants have to learn through interaction in different scenarios. All users in this study have had experience on using e-learning courses for at least one month.

\section{Theoretical background}

A significant body of research has focused on identifying various factors that influence user acceptance behaviors. In particular, the technology acceptance model 
(TAM), introduced by Davis and his colleagues [9] [10]. TAM has received considerable attention and has been established as a parsimonious and powerful model for explaining and predicting usage intentions and acceptance behaviors. TAM theorizes that an individual's actual system usage is determined by behavioral intention, which is jointly determined by perceived usefulness and perceived ease of use. Perceived usefulness is the extent to which a person believes that using the technology will enhance his or her job performance. Perceived ease of use is the extent to which a person believes that using the technology will be free of effort [9]. Behavioral intention is defined as the extent to which an individual intends to perform a specific behavior [10].

Bhattacherjee [2] argued that the eventual success of a new technology is more dependent on users' continued usage of the system rather than on their initial adoption. Bhattacherjee then developed a model based on an expectation-confirmed model and empirically tested it with acceptable results. The model is rooted in the expectancy-confirmation paradigm, which regards a user's continued usage decisions similar to a consumer's repeat purchase decisions. The model predicts users' intentions to continue usage of an IT system with three antecedent constructs: (1) user satisfaction; (2) extent of user confirmation; and (3) post-adoption expectations, represented as perceived usefulness.

Recent findings on intrinsic motivation and self-efficacy in social psychology indicate that enjoyment plays important roles in determining a person's behavior. Davis et al [11] put enjoyment followed the construct of perceived ease to use. As staff has to sacrifice their personal time to learn at home, the user will look for more pleasure on using the e-learning course based on the opportunity cost concept. Hence, it is proposed that enjoyment should be the precedent construct to perceived usefulness and perceived ease of use of the model and should have more coverage than the construct of confirmation as suggested by Bhattacherjee [2] in this case. According to DeLone and Mclean [12] and Seddon [3] on IS Success Model, the construct of system quality, information quality and service quality would affect user satisfaction. In combining the recent theoretical developments, the following framework is proposed to understand how individuals will continue to use the business and management e-learning courses:

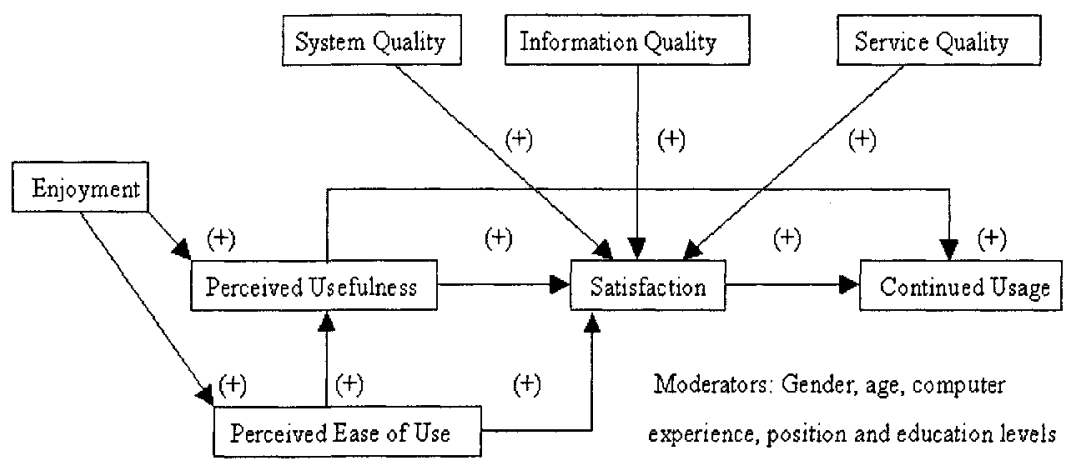

Figure 1-The proposed theoretical model 
It is proposed that enjoyment, like confirmation as defined by Bhattacherjee [2], will increase the perceived usefulness and ease of use of the system. Perceived ease of use will increase the perceived usefulness of the e-learning course. The perceived usefulness will increase the user satisfaction and that will encourage the learner to use the e-learning course again. The perceived usefulness, combining with system quality, information quality and service quality will increase the user satisfaction. The user satisfaction will lead to the continued usage of the e-learning course.

\section{Research method}

This research was a cross-sectional study that obtained information on variables in different contexts but at the same time. The data was collected over a short period (from Oct 2004 to Dec 2004). As it was a field experiment, there may be confounding and extraneous variables that obscured the effects of another. Hence, Structural Equation Modeling (SEM) was adopted. The goal of the SEM analysis was to determine to what extent the theoretical model was supported by sample data.

\section{Data collection method and pilot test of the questionnaire}

Questionnaire-based data-gathering technique was used. The items of the questionnaire were drawn from the literature. The questionnaire was also translated into Chinese to suit the needs of respondents who were not fluent in English. A pilot study of a group of 10 people was undertaken to ensure the items were adapted appropriately to the study context. The purpose was to find out potential problems and misunderstandings of instructions and question items. After the pilot test, some adjustments were necessarily made to represent the ideas clearly.

To control the variation of different types of e-learning courseware, such as from various vendors on different subjects such as language, computer skills and business, the research intended to narrow down the variation by choosing one vendor and one type of business courseware so that on instructional design, navigation and the look and feel, the courseware were standardized for comparison. The target population was a group of Hong Kong people using the business and management e-learning courses provided by a market leader in Hong Kong. The population was employees from 19 corporations. Stratified sampling was used to identify the number of sampling corporations (see Table 2).

The largest corporations in each sector were invited to participate in this research. The Human Resources Department of that invited corporation distributed the questionnaires to all the users. The participant was required to complete the questionnaire and send it directly to the researcher using a pre-stamped envelope. The six participating organizations include one multinational bank in Hong Kong, one public utility corporation, one local bank, one container service company and one local technology firm. The questionnaires collected from the sixth company, a small local e-commerce organization, were used to validate the calibrated model. 


\begin{tabular}{|c|c|c|}
\hline Type of Organization & No. in Population & No. of Sample \\
\hline Multinational corporations & 3 & 1 \\
\hline Public utility companies & 3 & 1 \\
\hline Large private organization & 6 & 2 \\
\hline Small local enterprises & 7 & 2 \\
\hline Total & $\mathbf{1 9}$ & $\mathbf{6}$ \\
\hline
\end{tabular}

Table 2 - The selection of the stratified samples

A total of 700 questionnaires were sent to the five corporations' human resources department for onward delivery to their staff. After collecting only 176 questionnaires as at 30 November 2004, the key coordinators of the five respective organizations were asked to remind their staff to return the questionnaire. An extra 41 questionnaires were later collected as at 31 December 2004. The response rate was $31.0 \%$. As the response rate was higher than the $20 \%$ response rate as identified by $\mathrm{Yu}$ and Cooper [13], non-response bias was not a serious problem in this research.

Of the collected 217 completed questionnaires, five questionnaires were found to be incomplete in some items and were discarded. Only 212 questionnaires were used for data analysis. The response rate became $30.3 \%$ that was still acceptable. According to the sample size requirement stated by Levine et al [14, p.443], it was safe to conclude that there were sufficient number of respondents to support the findings at $95 \%$ confidence level and at $7 \%$ sampling error.

The results from the first collected batch were compared to the second collected batch. It was found that there was no statistically significant difference. To overcome the potential bias and sterility of a single-method approach, this research conducted a data triangulation investigation in which a different set of data was collected at different times and strata of the study. The separate data was collected in Jan 2005 from an e-commerce company (the sixth company). 15 completed questionnaires were collected from the sixth company that had only 50 users for validation purposes. The response rate was $30 \%$ and was acceptable. It was found that there was no statistically significant difference between the calibration and validation sample.

\section{Examination of the data}

According to Joreskog [15], observations on a 7-category Likert scale represent responses to a set of ordered categories. This study followed the recommendation of Joreskog [15] to examine the data by LISREL.

\section{Instrument validation}

A confirmatory factor analyses was performed on the measurement model. The fit of the measurement model was estimated with different indices. The goodness- 
of-fit (GFI) and the adjusted goodness-of-fit (AGFI) were both 1.00. The values of the normalized fit index (NFI) was 0.97 . The values of the non-normalized fit index (NNFI) and comparative fit index (CFI) were respectively 0.98 and 0.99 which indicated good model fit (Chau, [16]). The observed values for root mean square residual (RMSR) and root mean square error of approximation (RMSEA) were respectively 0.074 and 0.057 , which were within the recommended cutoff values of 0.10 for RMSR and 0.08 for RMSEA for goodness-of-fit (Chau, [16]).

The psychometric properties of the constructs and items were summarised in Tables 3 and 4 . The convergent validity of the instrument was assessed by the composite reliability and average variance extracted. The composite reliability estimate for each construct ranged from 0.83 to 1.00 , suggesting an acceptable level of reliability (Hair, et al., [17]). The average variance extracted (AVE), ranging from 0.66 to 1.00 , were all above the recommended 0.50 level (Hair et al., [17]). According to Fornell [18], factor loadings in excess of 0.70 could be considered excellent for convergent validity. All the factor loadings were greater than 0.70 . Following Hair et al's [17] guideline, all squared multiple correlations should be above the 0.40 threshold for convergent validity. In Table 3 , the squared multiple correlations of individual items were high, ranging from 0.52 to 1.00 . In Table 4 , the average variance extracted for each construct was greater than the squared correlations between it and all other constructs. It indicated good discriminant validity (Fornell and Larcker, [19]).

\begin{tabular}{|l|l|l|l|l|l|l|l|l|}
\hline & USE & SATIS & PU & PEU & ENJ & SYSQ & IQ & SQ \\
\hline USE & $\mathbf{0 . 8 5}$ & & & & & & & \\
\hline SATIS & 0.31 & $\mathbf{1 . 0 0}$ & & & & & & \\
\hline PU & 0.81 & 0.10 & $\mathbf{0 . 9 7}$ & & & & & \\
\hline PEU & 0.44 & 0.75 & 0.28 & $\mathbf{0 . 8 8}$ & & & & \\
\hline ENJ & 0.36 & 0.56 & 0.24 & 0.48 & $\mathbf{0 . 9 5}$ & & & \\
\hline SYSQ & 0.12 & 0.24 & 0.06 & 0.11 & 0.23 & $\mathbf{0 . 8 3}$ & & \\
\hline IQ & 0.23 & 0.42 & 0.12 & 0.23 & 0.48 & 0.24 & $\mathbf{0 . 8 6}$ & \\
\hline SQ & 0.10 & 0.11 & 0.06 & 0.13 & 0.27 & 0.13 & 0.36 & $\mathbf{0 . 9 5}$ \\
\hline
\end{tabular}

Table 4-Construct correlation and discriminant validity 


\begin{tabular}{|c|c|c|c|}
\hline Construct & & $\begin{array}{l}\text { Factor } \\
\text { Loading }\end{array}$ & $\begin{array}{c}\text { Squared } \\
\text { Multiple } \\
\text { Correlations } \\
\end{array}$ \\
\hline \multicolumn{4}{|c|}{$\begin{array}{llll}\text { Continued Usage } & \mathrm{R}^{2}=0.37 & \text { Reliability }=0.85 & \mathrm{AVE}^{*}=0.66 \\
\end{array}$} \\
\hline USE1 & I frequently use my company's e-learning solution & 0.72 & 0.52 \\
\hline USE2 & $\begin{array}{l}\text { I have completely integrated the e-learning solution in my } \\
\text { personal development activity }\end{array}$ & 0.78 & 0.61 \\
\hline USE3 & I fully use the capabilities of the e-learning solution & 0.92 & 0.84 \\
\hline \multicolumn{4}{|c|}{ Satisfaction $\quad \mathrm{R}^{2}=0.53 \quad$ Reliability $=1.00 \quad \mathrm{AVE}=1.00$} \\
\hline SATIS1 & The e-learning solution is efficient. & 0.99 & 0.99 \\
\hline SATIS2 & The e-learning solution is effective. & 1.00 & 1.00 \\
\hline SATIS3 & I am satisfied with the e-learning solution. & 1.00 & 1.00 \\
\hline \multicolumn{4}{|c|}{ Perceived Usefulness $R^{2}=0.24 \quad$ Reliability $=0.97 \quad$ AVE $=0.88$} \\
\hline PU1 & Using e-learning improves my job performance & 0.95 & 0.90 \\
\hline PU2 & Using e-learning in my job increases my productivity & 0.97 & 0.94 \\
\hline PU3 & Using e-learning enhances my effectiveness in my job & 0.94 & 0.88 \\
\hline PU4 & I find e-learning to be useful in my job & 0.88 & 0.78 \\
\hline \multicolumn{4}{|c|}{ Perceived Ease of Use $\quad R^{2}=0.47 \quad$ Reliability $=0.88 \quad$ AVE $=0.70$} \\
\hline PEU1 & I find e-learning to be easy to use & 0.77 & 0.59 \\
\hline PEU2 & I find it easy to get e-learning to do what I want it to do. & 0.82 & 0.67 \\
\hline PEU3 & $\begin{array}{l}\text { My intention to use e-learning is clear and } \\
\text { understandable }\end{array}$ & 0.92 & 0.85 \\
\hline \multicolumn{4}{|c|}{ Enjoyment $\quad$ Reliability $=0.95 \quad$ AVE $=0.87$} \\
\hline ENJ1 & I have fun using the e-learning courses & 0.91 & 0.83 \\
\hline ENJ2 & Using the e-learning courses is pleasant & 1.00 & 1.00 \\
\hline ENJ3 & I find using the e-learning courses to be enjoyable & 0.88 & 0.77 \\
\hline \multicolumn{4}{|c|}{ System Quality $\quad$ Reliabilit } \\
\hline SysQ1 & $\begin{array}{l}\text { The network connection to internet has been satisfactory } \\
\text { while accessing }\end{array}$ & 0.92 & 0.84 \\
\hline SysQ2 & The rate at which the information displayed is enough & 0.75 & 0.57 \\
\hline \multicolumn{4}{|c|}{$\begin{array}{lll}\text { Information Quality } & \text { Reliability }=0.86 \quad \text { AVE }=0.67 \\
\end{array}$} \\
\hline IQ1 & I understand the terms used. & 0.76 & 0.58 \\
\hline IQ3 & The content relates well to my learning needs. & 0.84 & 0.70 \\
\hline IQ4 & The content is accurate & 0.85 & 0.72 \\
\hline \multicolumn{4}{|c|}{ Service Quality } \\
\hline SQ7 & $\begin{array}{l}\text { I found my IT/HR department to provide consistently } \\
\text { good solutions }\end{array}$ & 0.85 & 0.72 \\
\hline SQ9 & My IT/HR department provides service as I require it. & 0.96 & 0.92 \\
\hline SQ10 & $\begin{array}{l}\text { My IT/HR department delivers support in a timely } \\
\text { manner. }\end{array}$ & 0.95 & 0.91 \\
\hline
\end{tabular}

AVE = Average Variance Extracted 


\section{Empirical results}

According to Joreskog [6], robust diagonal weighted least squares (DWLS) estimation method was recommended to estimate the coefficients of the associations among the variables. All the hypothesized paths were significant. In summary, the proposed model accounted for $37 \%$ of the variance in users' continuance usage, $54 \%$ of the variance in user satisfaction, $24 \%$ of the variance in perceived usefulness and $47 \%$ of the variance in perceived ease of use.

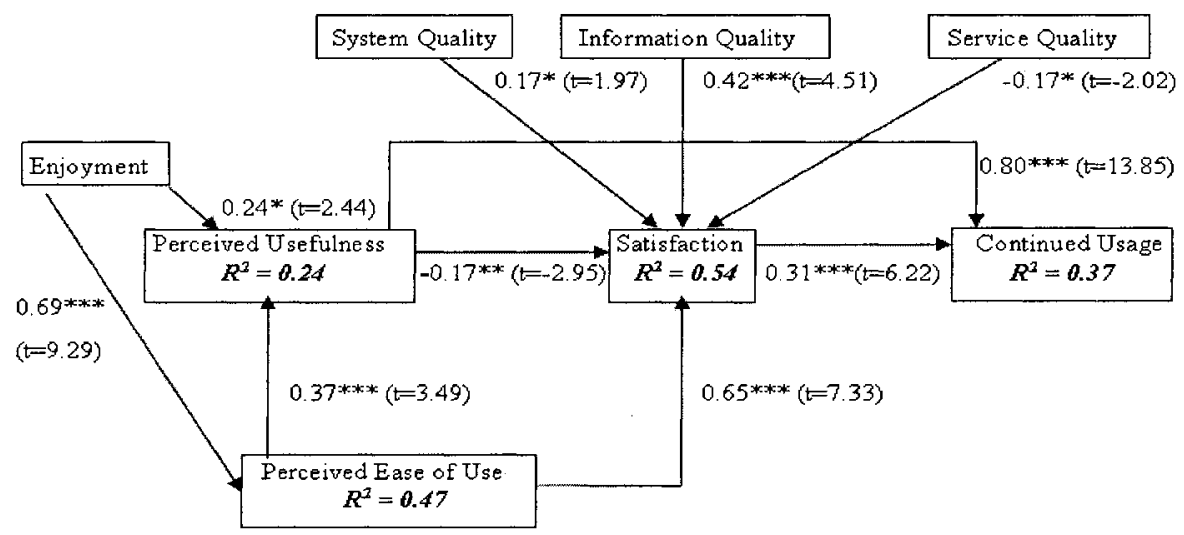

* for $\mathrm{p}<0.05$ (i.e. $t=1.96$ )

** for $p<0.01$ (i.e. $t=2.58$ )

t** for $p^{\varepsilon=0.001}$ (i.e. $t=3.29$ )

\section{Figure 2 - The results of the proposed theoretical model}

The model was compared for different groups of people. It was found that there was invariance across the male and female respondents, across managers and nonmanagers, and across respondents with less than 10 years experience in using computer as compared with respondents with 10 years or more experience in using computer. However, the model was different between groups of people who were aged 36 and above and group of people who were below 36, and between groups of people who were university graduates and non-university graduates.

\section{Discussion}

Two major factors, user satisfaction and perceived usefulness, were found to be significant in affecting the continued usage of the business and management $e-$ learning course. Hence, the developer of the e-learning course should be assured that the users are satisfied with the solution and with relevant and useful information in the course. The user satisfaction is positively related to the perceived ease of use of the system, information quality and system quality but negatively related to service quality and perceived usefulness. If the respondent needs more technical service from the companies, it will lower the satisfaction for using the e-learning course. Hence, the corporation should ensure that the e-learning courses are easy to operate, 
with relevant information and can be downloaded smoothly by ensuring a stable network flow. In addition, a prompt response to the technical enquiry was also needed.

Interestingly, if the user has a high-perceived usefulness of the e-learning course, they may be dissatisfied. It may be because of the limitation of the content that may not be truly interactive like a normal classroom. Based on adult learning theory, respondents expect to have more immediate feedback on their interaction with other participants in the classroom rather than using e-learning course for self-study.

According to this research, enjoyment is a key construct that affects the perceived usefulness and perceived ease of use. It reinforces the importance of the psychological factor in learning.

The proposed model is quite robust as it is not affected by different collection periods (first collection batch vs last collection batch) and sample (calibrated vs validation). It is interesting to know that the model is not affected by gender (male vs female), position (manager vs non-manager), and computer usage experience (10 years or more vs less than 10 years). However, the model is different between groups of different age (aged 36 and above vs below 36) and educational level (university graduates vs non-university graduates). It shows there may be some difference in the model when respondents are of different education level and of different age group. However, the present analysis tool cannot state where the difference is.

\section{Conclusion}

This is a first attempt to explore the factors that influence the continued usage of a business e-learning course in Hong Kong Corporations. The proposed model has a moderate explanatory power for the continued usage $\left(\mathrm{R}^{2}=37 \%\right)$. The model fitted well with the data and has a high degree of validity and reliability.

Enjoyment will affect the perceived usefulness and the perceived ease of use of the e-learning courses. The perceived usefulness, perceived ease of use, system quality, information quality and service quality can enhance the user satisfaction on using the e-learning course. Assured of the user satisfaction and the perceived usefulness of the courses, respondents will continue to use the e-learning courses.

\section{Limitation of this research}

This research is a cross-sectional research. It would be more beneficial to observe the change of the user expectation, thus the subsequent change of the user satisfaction and the continued usage, say within a year. It is commonly accepted that the user's expectation would change afterward. It will certainly lower the satisfaction level and the usage pattern. Future research can put more emphasis on the integration of the human factor interaction and social influence on the continual usage of the system. 


\section{References}

1. V. Venkatesh, M.G. Morris, G.B. Davis, and F.D. Davis, User Acceptance of Information Technology : Toward a Unified View, MIS Quarterly 27(3) 425-478 (2003).

2. Bhattacherjee, Understanding Information Systems Continuance: An ExpectationConfirmation Model. MIS Quarterly 25(3) 351-370 (2001).

3. P.B. Seddon, A respecification and extension of the DeLone and McLean model of IS success, Information Systems Research 8(3) 240-253 (1997).

4. K. Frankola, Why online learners drop out, Workforce, 80 (October) 53-60 (2001)

5. J. Moshinskie, How to keep e-learners from e-escaping, in The ASTD E-learning handbook, edited by A. Rosette (New York, McGraw-Hill, 2002) pp. 218-233.

6. G. Piccoli, R. Ahmad, and B. Ives, Web-based Virtual Learning Environment : A research framework and a preliminary assessment of effectiveness in Basic IT Skills training, MIS Quarterly, 25(4) 401-426 (2001).

7. M.Y. Yi, and F.D. Davis, Developing and validating an observational learning model of computer software training and skill acquisition, Information Systems Research 14(2) 146-169 (2003).

8. ASTD, A Vision of e-Learning for America's Workforce - Report of the Commission on Technology and Adult Learning. (25 Jan 2005) ; http://www.nga.org/cda/files/ELEARNINGREPORT.pdf

9. F.D. Davis, Perceived Usefulness, Perceived Ease of Use and User Acceptance of Information Technology, MIS Quarterly 13(3) 319-340 (1989).

10. [F.D. Davis, R.P. Bagozzi, and P.R.Warshaw, User Acceptance of Computer Technology: A Comparison of Two Theoretical Models. Management Science 35(8) 982-1003 (1989).

11. F.D. Davis, R.P. Bagozzi, and P.R. Warshaw, Extrinsic and intrinsic motivation to use computers in the workplace. Journal of Applied Social Psychology 221111 $1132(1992)$.

12. [W.H. DeLone, and E.R. McLean, The DeLone and McLean Model of Information Systems Success : A Ten-Year Update. Journal of Management information Systems 19(4) 9-30 (2003).

13. J. Yu, and $\mathrm{H}$. Cooper, A qualitative review of research design effects on response rates to questionnaires, Journal of Marketing Research 20(1) 36-44 (1983).

14. D. M. Levine, M. L. Berenson, and D. Stephen, Statistics for Managers, 2nd edition (Upper Saddle River, New Jersey, Prentice Hall, 1999).

15. K.G. Joreskog, Structural Equation Modeling with Ordinal Variables using LISREL (December 20, 2005). http://www.ssicentral.com/lisrel/techdocs/ordinal.pdf.

16. P.Y.K. Chau, Reexamining a Model for Evaluating Information Center Success Using a Structural Equation Modeling Approach, Decision Sciences 28(2) 309-334 (1997).

17. J.T. Hair, R.E. Anderson, R.L. Thatham, and W.C. Black, Multivariate Data Analysis with Readings (Prentice Hall, New York, 1982).

18. C. Fornell, A Second Generation of Multivariate Analysis (Praeger, New York, 1982).

19. C. Fornell, and D.F. Larcker, Evaluating Structural Equation Models with Unobservable Variables and Measurement Error. Journal of Marketing Research 18(1) 39-50 (1981). 